\title{
Employee Engagement: The Influencing Factors and Enhancing Strategies
}

\author{
Quanhong Liu \\ School of Business \\ Jianghan University \\ Wuhan, China \\ qhliu@163.com
}

\author{
Xin Zhao \\ School of Business \\ Jianghan University \\ Wuhan, China \\ 342321534@qq.com
}

\begin{abstract}
The level of employee engagement directly affects personal behavior and business performance, thereby determining the competitiveness of a company. Awareness and understanding of the employee engagement situation is conducive to the rational development and utilization of human resources, improve business efficiency. This paper discussed the background, concept definition and measurement of the employee engagement. Based on the related theoretical model, analyzed the influencing factors of employee engagement from three aspects of individual characteristics, job characteristics and organizational environment. And put forward some specific strategies to promote corporate employee engagement from the employee recruitment, effective training, work design and other aspects.
\end{abstract}

Keywords-employee engagement; job burnout; business performance; Human Resource Management

\section{INTRODUCTION}

Employee engagement is a hot issue in the study of human resource management. A large number of studies show that the dedicated employees greatly affect the business performance indicators. In the service economy, employee engagement directly determines the efficiency and quality of service of employee. Thus affecting the enterprise customer satisfaction, and ultimately affect the corporate image and corporate profits. With the increasing complexity of the organizational environment, employee engagement plays an important role in enhancing the innovation ability and competitiveness of enterprise, and adapting to dynamic environment. November 2013 Gallup published the latest survey report, the results show that only $13 \%$ of employees in the whole world, their working state called engagement. While $87 \%$ of employees do not put into work, it also less likely to have efficiency. In such a severe environment, the research on the influence factors and strategies of employee engagement has important practical and theoretical significance.

\section{RESEARCH BACKGROUND AND DEFINITION OF EMPLOYEE ENGAGEMENT}

\section{A. Research Background of Employee Engagement}

How to play the role of people that is the problem for managers and academics to think about in the enterprise management process. Before 1970, the main theory of management is to control the thinking and behavior of employees through the rules and regulations. Academia pays attention to how to improve employee satisfaction, avoid job burnout, and ultimately achieve business goals.

Now, in the era of knowledge economy, the knowledge reserve and potential capacity of the employee have important influence on the enterprise performance. Due to the change in the way of work, strict control to play the role of the staff is no longer valid. Therefore, during this period the main theory of management is psychological motivation for employees, increase employee motivation through a series of measures, so as to enhance the work efficiency. With the change of management oriented, scholars begin to pay more attention to positive psychology, it also provide a theoretical basis for the study of employee engagement. Influenced by positive psychology, when the employee psychology and feelings get attention in the work, the employee satisfaction and happiness can have a positive effect on organizational performance.

Early, Gallup and other international consulting company researched relationship between employee engagement and business performance. At present, most of the research of employee engagement mainly from consulting practice, theoretical research is still scarce.

\section{B. Definition of Employee Engagement}

Kahn ${ }^{[1]}$ (1990) believes that employee engagement is the degree that organization members put themselves into work from physical, cognitive, emotional and their self-expression. Kahn pointed out employee engagement is the degree that employees combine ego and work roles in the process of creating enterprise performance.

Maslach et al. (2001) believe that engagement is characterized by efficacy, involvement and energy, which is the opposite of job burnout.

Harter ${ }^{[2]}$ (2002) believes that engagement depends on the degree of employees' psychological identity work, job satisfaction and vigor.

Schaufeli et al. ${ }^{[4]}$ (2002) believe that employee engagement is characterized by vigor, dedication and absorption. It is a cognitive status of positive work, which is not an instantaneous state and is not limited to individual or behavior. 
Hewitt Associates believes that engagement is a kind of state with wisdom and emotion. It mainly in three aspects: say, stay and strive. Employees often highly praise their company to their colleagues, potential colleagues, especially to customers. Employees are eager to stay in the organization and exert extra work to make the company profitable.

\section{Measurement of EMPloyeE Engagement}

For different considerations of business practice and academic research, enterprises and scholars have adopted different ways to measure employee engagement. Commercial consulting company often use the Q12 questionnaire of Gallup, some consulting companies also develop their own model of the questionnaire according to the existing model. In the academic research field, there are measurement questionnaire of May et al, ${ }^{[3]}$ UWES (Utrecht work engagement scale) developed by Schaufeli et al. Leaders should be based on their own development strategy, combined with industry characteristic and job characteristics, the eventual choose the appropriate measurement questionnaire.

Gallup spent nearly 40 years on the development of the psychological measurement tools called GWA (Gallup workplace audit). It contains general satisfaction items and 12 specific items, which is used to measure the employee engagement and working environment. Practice has proved that 12 issues are fully reflected in staff retention, profits, efficiency and customer satisfaction four key indicators. The core idea of Gallup based on advantage theory, individuals and enterprises should avoid weaknesses, play their own advantages is the most efficient way. Q12 mainly tend to measure engagement of the team and the organization level, this method is more used in the field of business consulting.

On the basis of Kahn theory, May et al ${ }^{[3]}$ take the physical, cognitive and emotional as the three dimensions of employee engagement, but analysts did not get three completely independent dimensions. Thus they selected one of 13 projects scale measuring employee engagement. This questionnaire survey is mainly inclined to measure the individual level of the employee engagement.

MBI (Maslach Burnout Inventory) was developed by Maslach(1997), which initially contained three job burnout dimensions: exhaustion emotional, depersonalization and personal accomplishment. With the development of positive psychology, Schaufeli et al. prepared UWES scale through the interviews of high performance employees. UWES is gradually replacing MBI, becoming the mainstream tool of measurement in academic research field.

Thus, there are some differences in the understanding of employee engagement in different enterprises and scholars, but it is certain that the diversity of employee engagement. Employee engagement includes the employee's own commitment to the work roles, team roles, and organizational roles. Now the measurement tool is still biased in favor of a single dimension or cannot effectively verify the multidimensional nature of the scale, and focus on the role of the work itself or the organization itself. With the evolution of the theory of employee engagement, the employee engagement is not only confined to the individual, but also includes the relationship among the individual, job and organization. Therefore, if the company cannot effectively integrate three levels of employee engagement structure from work roles, job roles, and organizational roles, and make the corresponding measurement scale, it may cause the inconsistent of the theoretical level, analysis level and measurement level, leading to the gap between theory and practice. ${ }^{[5]}$

\section{INFLUENCING FACTORS OF EMPLOYEE ENGAGEMENT}

\section{A. Individual Characteristics}

The employee engagement is individual awareness of working hard, so it depends on the differences of individual characteristics of employees. Employee engagement has a great relationship with employee's gender, age and other demographic variables. ${ }^{[6]}$ Schaufeli and Bakker studies show that male engagement is slightly higher than female. There were significant differences between male and female in three factors: energy, active participation and efficacy, which show a weak relationship between engagement and gender. The results consistent with the present social situation, male employees feel more life pressure than female. Male employees prefer to challenge higher goals, focusing on career development. The employee engagement will improve with the growth of age. This is related to the increase of employee loyalty to the company. The research of Robinson are inconsistent with this, it shows that employee engagement is influenced by the working age, and the longer the working age is, the lower the employee engagement is. When the working age is increased, employees are familiar with the work, but they can get less information and skills which will cause them to feel no sense.

In addition, compressive ability, responsibility and other personality traits will also have important influence on employee engagement. A strong sense of responsibility and engagement are directly reflected in everyone life and values. The research shows that the responsibility has a positive prediction effect on the engagement.

\section{B. Job Characteristics}

Employees always want to get psychological satisfaction from work; there is a contractual relationship between the individual and the job, which depends on the individual's psychological status in the process of job roles. Employees have a sense of accomplishment, a sense of belonging and other basic psychological needs. Environment to meet those needs makes employees feel pleasure, and then encourage employees to enjoy the present work. The employees will evaluate the work environment, work content and other factors, generates a psychological sense of significance and satisfaction, thereby affecting employee engagement. When employees identify with the significance and challenge of work, and have some autonomy, they will spend more energy to work. Job characteristic is an important factor affecting employee engagement which can satisfy the needs of the employees and motivate themselves. Some of the consulting company's survey found that some job characteristics on the front row in the impact of employee engagement. Towers Perrin survey showed that the challenges of work, decision-making power, and the completion of the work needed resources are seriously affect 
engagement level factors. The Gallup Q12 also shows that the influence of working environment on employee engagement from the side. The study found that the working environment which can exert employee talent will play a greater impact on the level of employee engagement.

\section{Organizational Environment}

Today, employees are well aware of their position in the enterprise, know that they have a responsibility to consolidate their position through continuous learning. They expect that managers can provide them with training opportunities, so that they can continue to learn; enterprise can develop effective career planning, so that they continue to grow; enterprise can pay the appropriate remuneration as a return on their contribution to the performance. ${ }^{[7]}$ The factors that affect the employee engagement, which are closely related to the survival and development needs of employees play a primary role. Salary for employee engagement plays an irreplaceable role. When their capacity and the performance lack of appropriate return, low employee engagement is difficult to avoid. The improvement of health care factors, such as salary, cannot make employee satisfaction, but it can reduce their unsatisfactory. Random expansion of health factors will not only lead to disappointment of employee, the enterprise former material incentive and moral investment will also face the risk of emptying. Employee engagement is influenced by reduction of the employee satisfaction. ${ }^{[8]}$ According to the social exchange theory and the principle of reciprocity, higher organizational support can make employees feel that they have the obligation to return the organization to give their own benefits and opportunities. Employees will often take the initiative to help when the organization needs it. Some needs of the employees to be satisfied only through the organization, their psychological and behavior are restricted and influenced by the organization. Good corporate culture and values will increase the loyalty of employees. When the enterprise and employees trust each other, employee engagement will be greatly enhanced.

\section{STRATEGIES TO ENHANCE THE EMPLOYEE ENGAGEMENT}

\section{A. Emphasis on Employee Recruitment}

Engagement is largely influenced by the individual characteristics of the employee, employee's values responsibility and other characteristics will affect the employee engagement. Therefore, when companies recruit employees, they need a preliminary understanding of the staff's personality, motivation, values and responsibilities, and past work experience, consider the skills required for the job, and see whether the individual characteristics of employees and job requirements are matched. When the deviation occurs, employees cannot fully play its own value, it will reduce employee satisfaction. In addition, it must take into account whether the candidates comply with the corporate culture. Through the use of employee engagement measurement tool that is suitable for enterprise development strategy can have a preliminary understanding of the candidates.

\section{B. Effective Training}

In the face of complex and diversified economic development, enterprises must strengthen the training of employees; improve the competitiveness of enterprises and soft power to meet new challenges. A good training program can fully mobilize the enthusiasm of the trainees; enhance the overall quality of employees, which is a win-win for both employees and enterprises. For the employees, it will enhance their professional capabilities and comprehensive quality through training. For enterprises, with the strengthening of employee capacity, it will help the work smoothly, so as to improve corporate performance. Effective training should nurture core competencies and enhance their own survival and development as a starting point, this is a long process. The skills training can improve the competence of employees, thereby increasing employee job resources, thereby enhancing work engagement. Attitude training can improve the staff's working motivation, increase the staff's enthusiasm and cultivate the sense of meaning and satisfaction. Corporate culture training can make employees more understanding of the enterprise and work environment, so that employees can fundamentally like the enterprise and the work, they are willing to pay extra energy and emotion for the work. Training should reflect the differences, scientific, interactive, coaching employee around ability and psychology, mobilize the enthusiasm of employees and improve employee engagement.

\section{Harmonious Workplace}

Workplace design will affect individual emotional intelligence of employee, which will affect the work performance. Therefore, leaders have a responsibility to show a positive image to employees, to create trust and meaningful workplace. In addition, when the relationship between colleagues is harmonious, employees focus more into work rather than a variety of interpersonal conflicts. When corporate values and employee values match each other, it will increase employee's satisfaction. Harmonious workplace can meet the social needs of employees, improve employee engagement.

\section{Work Design}

In order to help employees get the meaning of work and the value of work, the effective work design should be carried out, so as to motivate employees into work. Therefore, in the design of the work, the enterprise must let the employees know the significance of the work, set reasonable work quotas. Work needs some challenges, thus completing the work will have a sense of satisfaction. Enterprises should ensure sufficient autonomy and control, and provide accurate and timely feedback information in the work process. The employees required to be flexible to use a variety of work skills in the work. Through effective target management, job rotation, job expansion and job enrichment to motivate employees, so that employees realize the significance of the work, get the internal incentive and enhance the employee engagement.

\section{E. Career Planning}

Employees are often concerned about the development of their own career, especially the new generation of employees, emphasis greatly on personal future prospects. Therefore, 
managers should combine the development of the enterprise itself and the individual development of the employee. Not only to enhance management practices, but also to develop a mutually acceptable development plan for each employee according to different individual characteristics of employees. Helps employees to have a career planning, and provide an environment for employees to understand themselves and develop themselves, let the employees have a clear goal to know how to learn in each stage of growth. Provide clear guidance for the professional development of employees, can enhance employees' confidence in the business and their own development, thereby increasing employee motivation and effectively improve employee engagement.

\section{F. Construct Corporate Culture}

Corporate culture is the guarantee to mobilize all employees to implement the enterprise strategy. In the new period, the construction of enterprise culture must be peopleoriented, pay attention to the human resources of enterprises. Give employees full respect and care, pay attention to their emotional needs, make them feel sense of belonging. Give employees a fair chance to participate in decision-making and show their talent. Mobilize the enthusiasm of the employees, so that they can enjoy the work independently, enhance employee self-fulfillment and the corporate identity. Enterprises advocate humane management can stimulate positive emotions of employees. The common value orientation will form the cohesion of the enterprise, and enhance the sense of mission and responsibility of the employees. A good corporate culture can help employees realize their own value and unite the people, enhance employee engagement.

\section{REFERENCES}

[1] W. A. Kahn, "Psychological Conditions of Personal Engagement and Disengagement at Work," J. Academy of Management Journal, 1990, 33(4): 692-724.

[2] J. K. Harter, F. L. Schmidt and T. L. Hayes. "Business-Unit-Level Relationship Between Employee Satisfaction, Employee Engagement, and Business Outcomes: A Meta-Analysis," J. Journal of Applied Psychology, 2002, 87(2): 268-279.

[3] D. R. May, R. L. Gilson and L. M. Harter. "The Psychological Conditions of Meaningfulness, Safety and Availability and the Engagement of the Human Spirit at Work," J. Journal of Occupational \& Organizational Psychology, 2004, 77(1): 11-37.

[4] W. B. Schaufeli, I. M. Martinez, A. M. Pinto, et al. "Burnout and Engagement in University Students: A Cross-National Study, " J. Journal of Cross-Cultural Psychology, 2002, 33(5): 464-481.

[5] L. Fang, K. Shi and F. Zhang,"Review of the Researches on Employee Engagement, " J. Human Resource Development of China, 2010, 22(5): 47-54.

[6] H. Yang and J. Liao, "Employee Engagement Present Situation Analysis and Future Prospects (In Chinese) ," J. Foreign Economics and Management, 2009, 31(5): 45-51.

[7] P. Wang, C. Liu and Q. Wang, "Research on the Influence Factors and Promotion Measures of Employee Engagement (In Chinese) ," J. China Management Informationization, 2011, 14(13): 81-83.

[8] Y. Li and K. Zhang, "New Trends in Job Burnout Research," J.Psychological Science, 2007, 30(2): 478-481. 